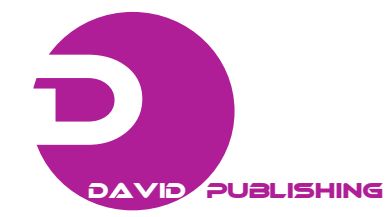

\title{
Perspectives of the Brazilian Poultry Industry for the Chinese Consumer Market
}

\author{
César Augustus Winck ${ }^{1,2}$, Miguelangelo Gianezini², Clandio Favarini Ruviaroº , João Armando Dessimon \\ Machado $^{2}$ and Homero Dewes ${ }^{2}$ \\ 1. University of West of Santa Catarina, Joaçaba 89600-000, Brazil \\ 2. Center for Studies and Researches in Agribusiness, Federal University of Rio Grande do Sul, Porto Alegre 91540-000, Brazil
}

Received: October 18, 2011 / Published: January 20, 2012.

\begin{abstract}
The objective of this article was to analyze the poultry and derivatives commerce between Brazil and China, taking into account the current market and the perspectives for the next years. The method used was the bibliographic review and analysis of secondary data from different sources, associated with the Market Orientation Theory and the Value Chain Theory. Nowadays, China is Brazil's main commercial partner in the international market, but taking into account the chicken meat and its derivatives, having Brazil as the first worldwide exporter and China, the second largest consumer, an effective commercial relationship has not been established yet. To understand the poultry market exchanges between Brazil and China, a framework was built to demonstrate the characteristics and factors found to influence country negotiations, considering current reality and future perspectives. Considering the Theory of Market Orientation, it is concluded that Brazil has effective conditions to consolidate itself as a major supplier of chicken meat and derivatives to China, because it shows determinant characteristics and market factors that allows the association of the national poultry value chain to the demands of the Chinese consumers, but some adjustments are needed in the sphere of international politics.
\end{abstract}

Key words: Chicken meat, market orientation, Brazil, China, agribusiness.

\section{Introduction}

Since 2005, Brazilian aviculture is a leading exporter in the international meat market, and occupies the third position in the world production of this product [1].

In Brazil, aviculture developed since the 1960s with the emergence of agribusiness groups targeting the sector and became competitive to a world level [2] by basing its productive chain in the principles of integrated production, low production costs associated with successive records in grain production (maize and soybean) [3], hygienic and sanitary quality of the herds, development of research and leading technologies for the productive sector [4], internationalization of enterprises [5] and volume of production in constant growth [6].

Corresponding author: César Augustus Winck, Ph.D., candidate in agribusiness, professor, researcher, research fields: agribusiness, supply chains. E-mail: cesar.cepan@gmail.com.
Poultry agribusiness has been driving large volumes of products (meat and derivatives) and consequently large amounts of money both in the internal and external market [3]. Considering that national poultry production is competitive and expanding, as well as internal and external consumption, new markets must be prospected [6], and among them, the Chinese is one of the most promising.

China is the country with the biggest world population (1.35 billion inhabitants), and even if its demographic growth is at incipient levels $(0.6 \%$ per year), there is no way to ignore the extreme potential demand of this country [7]. Thus, we must analyze the Chinese market from the perspective of their current and future marketing demands, taking into consideration all the aspects that may ease or hamper the commercial relationship Brazil-China for this market. 
Given the current situation and future prospects, the theoretical basis used was the Market Orientation Theory associated to the Value Chain Theory and the model applied was the one proposed by Grunert [8], to produce an analysis of the Chinese market for poultry meat and derivatives produced in Brazil today and for the next years.

\section{Theoretical Development}

\subsection{Market Orientation Theory}

Many papers have studied the influence of market orientation in various aspects within companies. These researches (Table 1) show that when a company implements market orientation this ends up bringing several benefits such as: increase in profitability [9], improved commitment and attitude of employees [10], directing the sales more final customer-oriented [11], besides allowing a position of sustainable competitive advantage after effectively applying the resources of the market orientation [12].

The market orientation allows the integration between business strategy and organizational culture present in enterprises [13], thus being considered a guide for strategical selection of decisions related to production and commercialization of products [14].

Basically the concept of market orientation comprehends five dimensions such as: orientation for the client, orientation for the competitor, cross-functional coordination, profit orientation and receptivity. When these five dimensions are satisfactorily completed, the enterprises tend to obtain an improvement in their results $[15,16]$.

The market orientation showed a positive relation with the return of assets [17], success in the launching of new products [9], improved profitability and growth in sales [18]. Besides that it allows the Constant search for market not yet served but with potential demand and enables the enterprises to direct their production to the administration of internal and external relationships, in the continuous improvement of products and organizational culture focused in the consumer [19].

The companies can respond to the market in two ways, one adaptive and the other pro-active [20]. In the pro-active one the company tries to change the market benefiting from it, as for example with a technological innovation. In the adaptive the company configures itself to the market in its current reality adapting to competitors, partners and clients.

\section{Table 1 Contribution of the authors, according to year, for the theory for market orientation.}

\begin{tabular}{|c|c|c|}
\hline Author (s) & Year & Theoretical contribution to the conceptualization \\
\hline Shapiro [21] & 1988 & $\begin{array}{l}\text { All organizations must get involved in the search for the best process, including: } \\
\text { comprehension, decision making and coordination with mutual commitment. }\end{array}$ \\
\hline Narver and Slater [17] & 1990 & $\begin{array}{l}\text { Enables continuous and superior performance for the company as it provides the } \\
\text { creation of superior value for buyers. Based on: Orientation for the client; Orientation } \\
\text { for the competitors; Cross-functional coordination; Organizational culture; Focus on } \\
\text { long term profit. }\end{array}$ \\
\hline Kohli and Jaworski [22] & 1990 & Concept of market intelligence (information about current and future needs of \\
\hline Jaworski and Kohli [10] & 1993 & consumers): market intelligence generation, dissemination and response of the \\
\hline Jaworski and Kohli [23] & 1996 & company to this intelligence. \\
\hline Day [24] & 1994 & $\begin{array}{l}\text { Companies build a complex set of experiences, knowledge and skills, representing a } \\
\text { superior skill in the understanding and satisfaction of the clients. The organization } \\
\text { creates subjective capacities that hinder the imitation by competitors. }\end{array}$ \\
\hline Deshpandé and Farley [25] & 1998 & $\begin{array}{l}\text { Set of activities, behaviours and processes related to continuous assessment and attend } \\
\text { the customer's needs. Does not consider the market orientation as an organizational } \\
\text { culture. }\end{array}$ \\
\hline Foley and Fahy [26] & 2004 & $\begin{array}{l}\text { Orientation to learning precedes market orientation. It relies on the construction and } \\
\text { use of information. }\end{array}$ \\
\hline Baker and Sinkula [27] & 2005 & $\begin{array}{l}\text { Success of new products is directly influenced by the degree of market orientation, } \\
\text { improving organizational performance. }\end{array}$ \\
\hline $\begin{array}{ll}\text { Gebhardt, } & \text { Carpenter } \\
\text { Sherry [28] }\end{array}$ & and 2006 & $\begin{array}{l}\text { Market orientation as essentially a process of cultural change, which takes place } \\
\text { through actions that the administration takes to introduce new cultural values. }\end{array}$ \\
\hline
\end{tabular}

Source: By authors (2010). 
The market orientation should not be disassociated from the educational learning process innovation and improvement of the organizational culture [29], inasmuch with the current marketing globalization the organizations only manage to become competitive after they achieve equal or better performance than their competitors [30].

This marketing globalization promoted the appearance of the Theory of Market Orientation associated with the internationalization of the organizations, entering the export performance in academic studies.

\subsection{International Market Orientation Theory}

The option to internationalize the company and the decisions of how to promote the entrance in new external markets imply in a number of risks and end up involving great wherewithal many times beyond the financial capability of the companies [31].

Internationalization is a strategic decision and needs the immediate identification of the products to be offered and the markets to be achieved. Furthermore, the most appropriate forms of access and maintenance in this market should be planned in advance [31].

The presence of the company overseas may occur gradually, normally starting in the process of indirect export and successively to direct export, licensing, Joint Venture and in a most advanced stage with direct foreign investments [32].
Table 2 presents the authors and their contributions for the Theory of Orientation for the International Market.

The reasons that lead a company to operate in foreign markets can be grouped into two factors: internal, originated in the company (characteristics, resources, objectives and strategies of the company) and external, originated externally (requests from abroad, government support of the country of origin or the host etc.) [31].

In Brazil, the internationalization of the companies is still very recent (end of the 60's) and was motivated by tax incentives and loans granted by the federal government and were available to all companies in all areas [33].

\subsection{Value Chain Theory}

The value chain [34] represents the group of activities carried out by an organization from its relation with the suppliers and productions cycles and of sale to the final distribution stage.

The study of the value chain allows an analysis of costs behaviour and the existing sources of means along with the differential potential in each process.

When a company achieves the cost leadership and differs in its product for the quality adding value to it, occurs what can be called a competitive advantage in the chain in which the company operates [35]. The product of an organization equally becomes part of the

Table 2 Contribution of authors, according to year, for the theory of market orientation, considering the internationalization and exporting performance.

\begin{tabular}{|c|c|c|}
\hline Author (s) & Year & Theoretical contribution to the conceptualization \\
\hline $\begin{array}{l}\text { Cadogan and Diamantopoulos } \\
\text { [36] }\end{array}$ & 1995 & $\begin{array}{l}\text { Orientation model for international market: cross-functional coordination, generation of } \\
\text { export intelligence, dissemination of export intelligence and response action. }\end{array}$ \\
\hline Zou, Taylor and Osland [37] & 1998 & $\begin{array}{l}\text { Export performance is a competitive differential in the market and is based on: financial } \\
\text { performance of exports; strategic performance of exports and perceived success in exports. }\end{array}$ \\
\hline $\begin{array}{l}\text { Cadogan, Diamantopoulos and } \\
\text { Mortanges [38] }\end{array}$ & 1999 & $\begin{array}{l}\text { Development of a scale to measure the degree of market orientation in foreign exporting } \\
\text { companies. }\end{array}$ \\
\hline $\begin{array}{l}\text { Matsuno, Mentzer and Rentz } \\
\text { [39] }\end{array}$ & 2000 & $\begin{array}{l}\text { Implantation of a particular strategy is a process of organizational adaptation to the market } \\
\text { and market orientation is fundamental. }\end{array}$ \\
\hline Garrido [40] & 2007 & $\begin{array}{l}\text { Development of a hybrid scale of valid model to measure the degree of orientation for the } \\
\text { external market of the Brazilian exporting organizations. }\end{array}$ \\
\hline Dalmoro [41] & 2007 & $\begin{array}{l}\text { Proposition of a theoretical model about the internal values and internationalization } \\
\text { strategies influencers of the external market orientation and exporting performance. }\end{array}$ \\
\hline
\end{tabular}

Source: By author (2010). 
value chain of its clients, being that the final differentiation of an organization lies in the role it and its products play in the value chain of the buyer.

The analysis of the value chain is important as the competitive advantage of an organization depends not only on the relationships it establishes internally but also in the way how it interacts with the indirect and direct suppliers and with its clients [42]. Besides this, with the market globalization there was a reduction of barriers of the global flow of information, ideas, production factors, technology and goods.

Some authors have associated the study of Value Chain to the Theory of Market Orientation (Table 3), allowing increase the analysis by considering not only the organization in an individual way but the whole chain in which is inserted.

The three key-elements for the analysis of the value chain are: entry barriers and income, governance, and different types of existing chains [34]. Considering this the companies have been adopting measures to improve the quality of their products and basing the production in modernization processes, updating of products, functional readjustment and chain update. The capacity to innovate assures a continuous improvement of the products and developing processes but does not guarantee improvement in economic results or in increase of market share.

The five factors that influence the degree of market orientation in a value chain are: heterogeneity and dynamism of markets for end user, chain configuration, regulations, competitive pressures and the trade associations [8].

\subsection{Poultry Industry in the World}

The world consumption of poultry meat has been growing year after year, getting to 2010 with a forecast of 73 million tonnes which correspond to an increase of 15.1\% comparing to the consumption of 2005 (Fig. 1).

Table 3 Contribution of authors, according to year, for the theory of market orientation, considering the analysis of value chain.

\begin{tabular}{lll}
\hline Author(s) & Year & Theoretical contribution to the conceptualization \\
\hline Baker [43] & 1999 & $\begin{array}{l}\text { Market orientation from the value chain. The degree of market orientation of a member } \\
\text { of the chain can affect the degree of guidance of the other members. }\end{array}$ \\
$\begin{array}{l}\text { Grunert et al. [8] } \\
2002\end{array}$ & 2005 & $\begin{array}{l}\text { Importance of managing channel relationships, including vertical integration, when } \\
\text { serving markets with high volatility of the end user. } \\
\text { Concept of mental models as a possible mediator between the factors that influence the } \\
\text { degree of market orientation and market-oriented activity. }\end{array}$ \\
\hline Grunert et al. [45] & 2010 &
\end{tabular}

Source: By author (2010).

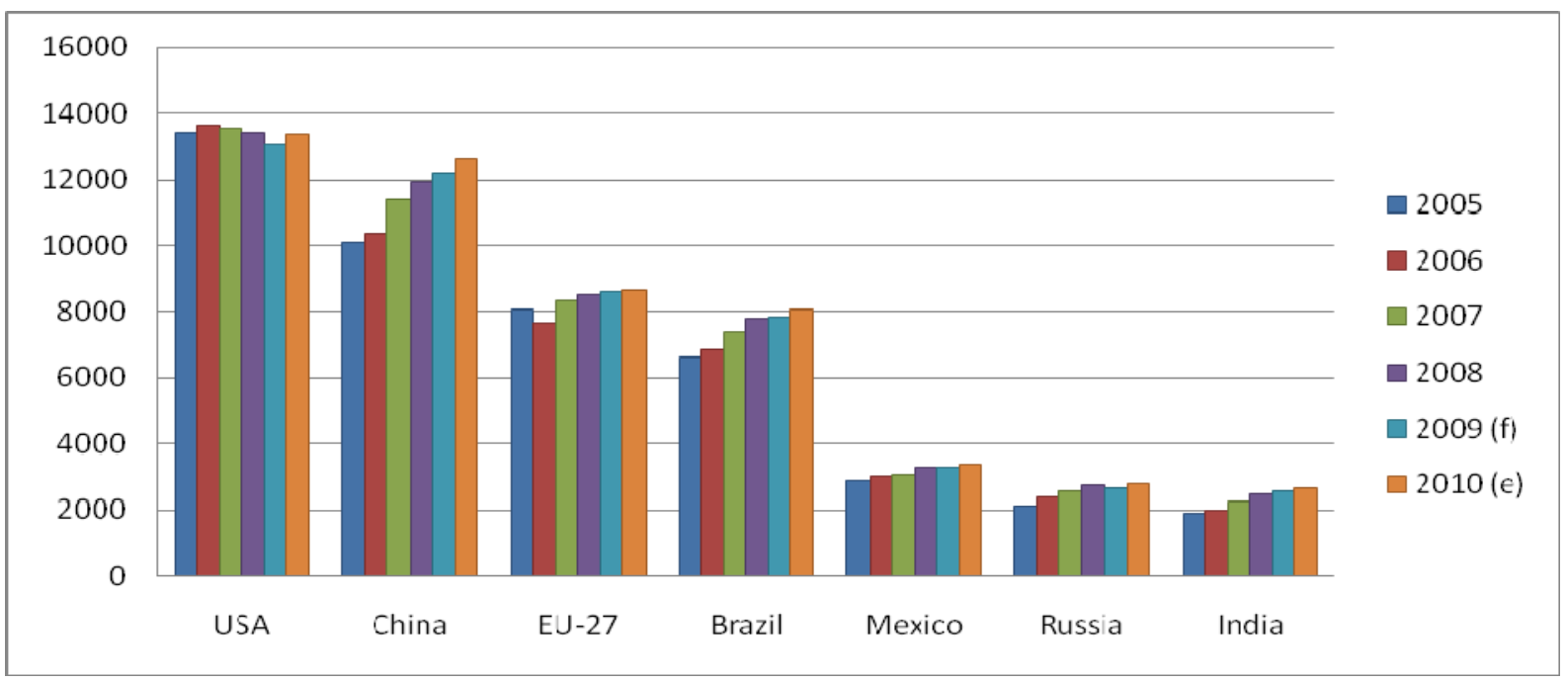

Fig. 1 World consumption of poultry meat per country 2005/2010 (thousands of tonnes). (f) forecast, (e) estimation. Source: Ref. [1]. 
The poultry meat is the second most consumed in the world, only behind the pork being the main consumers United States, China, European Union (EU-27), Brazil and Mexico [1].

China is the country where the consumption has increased most, reaching an increase of $20 \%$ in 2010 comparing to 2005. Brazil raised the consumption in 18\%, and the United States and European Union had virtually no increase in consumption over the past six years.

The world production of poultry meat jumped from 63.1 million in 2005 to 73.7 millions in 2010, corresponding to an increase of $14.4 \%$. Only China (18.4\%) and Brazil (18.5\%) reached a value above the global average, being that the USA reached 2.5\% increase, the European Union 5.8\% and Mexico 13.5\% (Fig. 2).

Brazil is the biggest world exporter of poultry since 2004 with $39.7 \%$ of the total exports of 2010 and the United States occupy the second position with 33.7\%. Considering these data, it is possible to visualize that these two countries alone account for more than $73 \%$ of total exports in the world (Fig. 3).

The other countries considered exporters had increases in the values in percentage since 2005, with exception of China and Kuwait that reduced 23.5\% and $27.8 \%$ respectively their exports. This reduction in the values exported by China can be explained by the growth in domestic consumption and the increase of the Chinese population.

The biggest importer of poultry in the world is Russia with $10.6 \%$ of the total, followed by the European Union (9.2\%) and Japan (8.8\%). The Middle East region, particularly countries like Saudi Arabia and United Arab Emirates have increased the imports of poultry in the last years. Asian countries also represent the new markets for the sale of poultry with a considerable growth in its imports from 2005 to 2010, for example China (64.4\%), Iraq (128\%) and Hong Kong (17.1\%) (Fig. 4).

\subsection{Poultry Industry in Brazil}

The Brazilian poultry industry has been increasing worldwide since the 70's when the exports started to become strong, and consequently it has increased the financial and technological investment in the production, slaughtering and processing of chicken [5].

From the decade of 1990, Brazil established itself as a worldwide leading producer of processed poultry [1], and in 2005, because of bird flu, the country started to

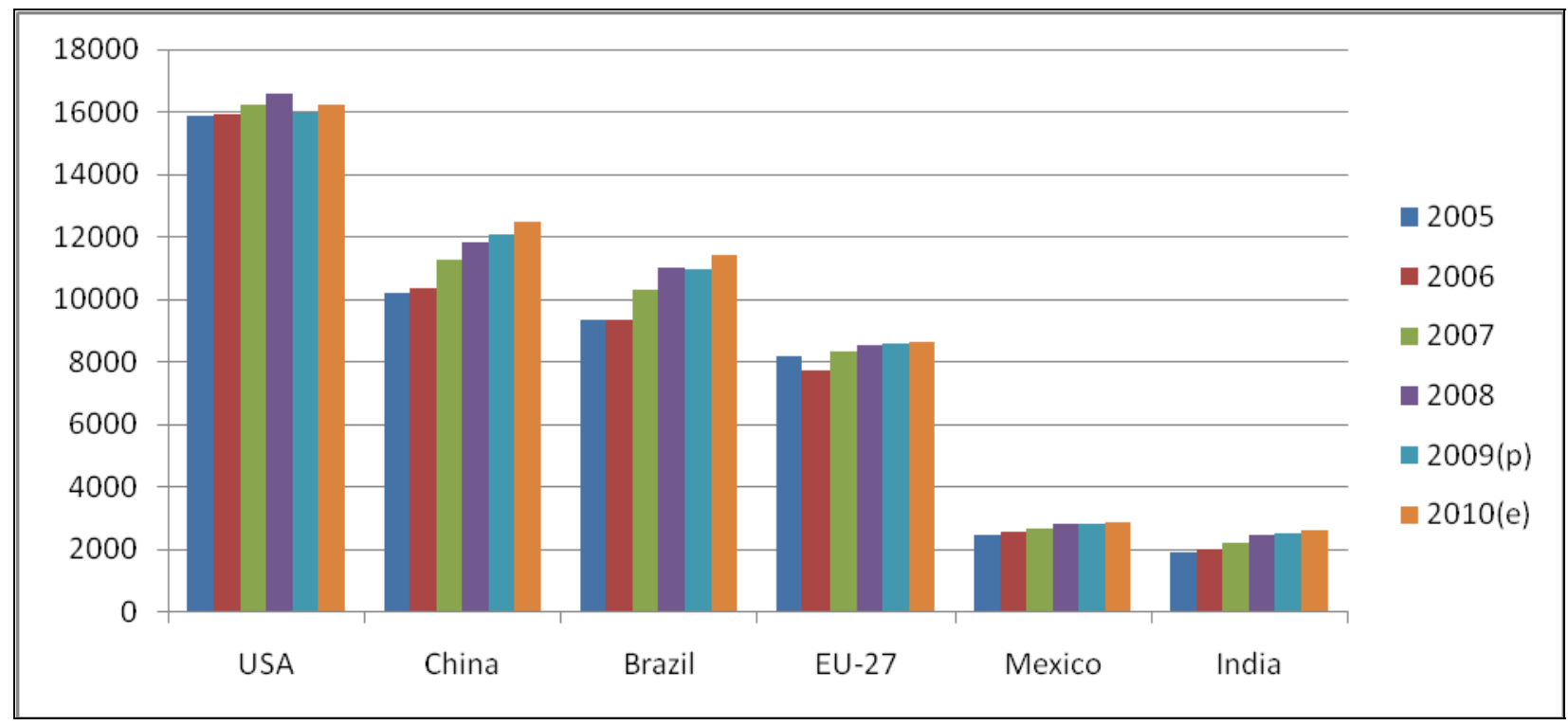

Fig. 2 World production of poultry meat per country 2005/2010 (thousands of tonnes). (p) forecast, (e) estimation.

Source: Ref. [1]. 


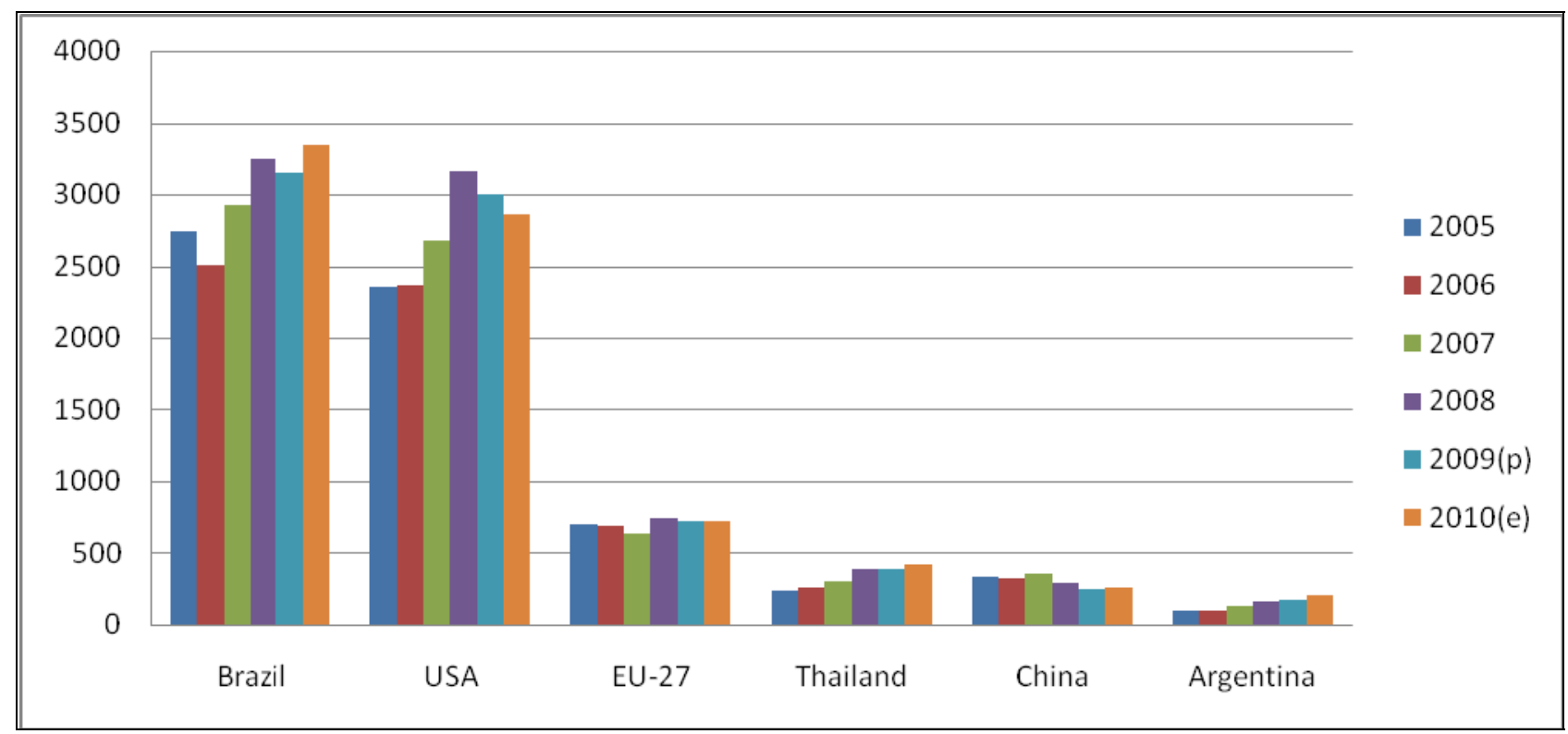

Fig. 3 World export of poultry meat per country 2005/2010 (thousands of tonnes). (p) forecast, (e) estimation. Source: Ref. [1].

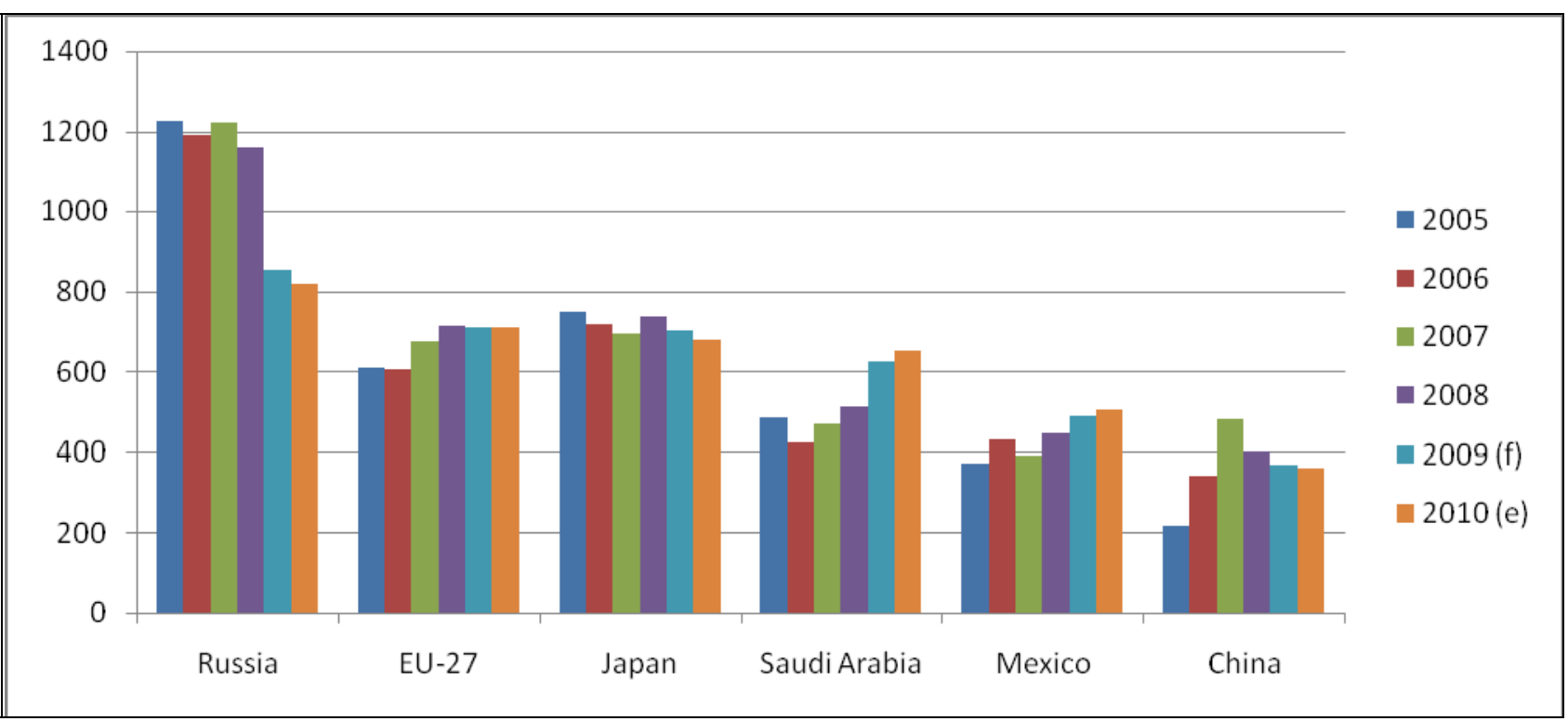

Fig. 4 World import of poultry meat per country 2005/2010 (thousands of tonnes). (f) forecast, (e) estimation.

\section{Source: Ref. [1].}

supply part of the world market dominated until then by Thailand that at the time was impeded to export because of the epidemic in Asia [46].

During the year 2009, Brazil produced 10.9 million/tonnes of poultry meat and although the world had faced a financial crisis in 2008, the production was kept stable with a reduction of only $0.03 \%$ in the total of production [1].
The country is world leader exporting poultry and its derivatives reaching in 2009 a volume of 3.6 million tonnes and serving more than 150 countries, but with a reduction of invoicing of US\$ 7 billion in 2008 to approximately US\$ 6 billion in 2009 [3] caused mainly by the devaluation of the dollar and the price fall of the poultry in the external market.

Brazilian consumption of poultry meat has remained at 
elevated levels for years, growing in average $2 \%$ to $3 \%$ and with a current consumption of 39 kilos, a lot lower than countries such as the Middle East that reached an annual consumption of 60 kilos per inhabitant [2].

The perspectives of this sector, that has $30 \%$ of its production directed to export with a growth in the last decade of $10 \%$ per year [3] generating directly and indirectly more than 5 million jobs, are optimistic.

Brazil has growing indexes of production and internal and external marketing, production costs lower than its main competitors [3] and technological domain in production and industrialization of the meat [4]. Also presents sanitary conditions of the herds under control (Influenza and Marek's Disease) and the increase of and the increase of unilateral and bilateral trade agreements, signed in the last years and that signalize the global interest for the poultry meat produced in Brazil [2].

Analizing the data from the Ministry of Agriculture (Fig. 5), which project the evolution of the national poultry industry for the next 10 years, considering a scenario of maintenance of the current growth indexes, it is perceived that Brazil has the capacity to attend with its production the internal consumption growth and to supply the demand of current and future buyers of poultry meat.

\subsection{China and Its Characteristics}

China has a socio-economic regime known as "socialist market economy" [47], which means, the socialist regime still resists in the relations of property and in the further areas from major centers, and the capitalist regime present in the relations of production and work especially in the more modern areas. These two models coexist governed by a specific political system, under control of a mono-party regime (Chinese Communist Party).

The Chinese economy was the one with the biggest growth in the world in the last thirty years reaching in 2008 a GDP of US\$ 4.2 trillion for a population of 1.35 billion inhabitants, reaching a GPD per capita of US\$ 3.154 [7]. When it is considered a GPD per sector it is perceived the country is mainly industrial with $49.2 \%$ of the GPD generated in this activity, the service sector with $40.2 \%$ of the GPD and the agriculture being responsible for only $10.6 \%$ [47].

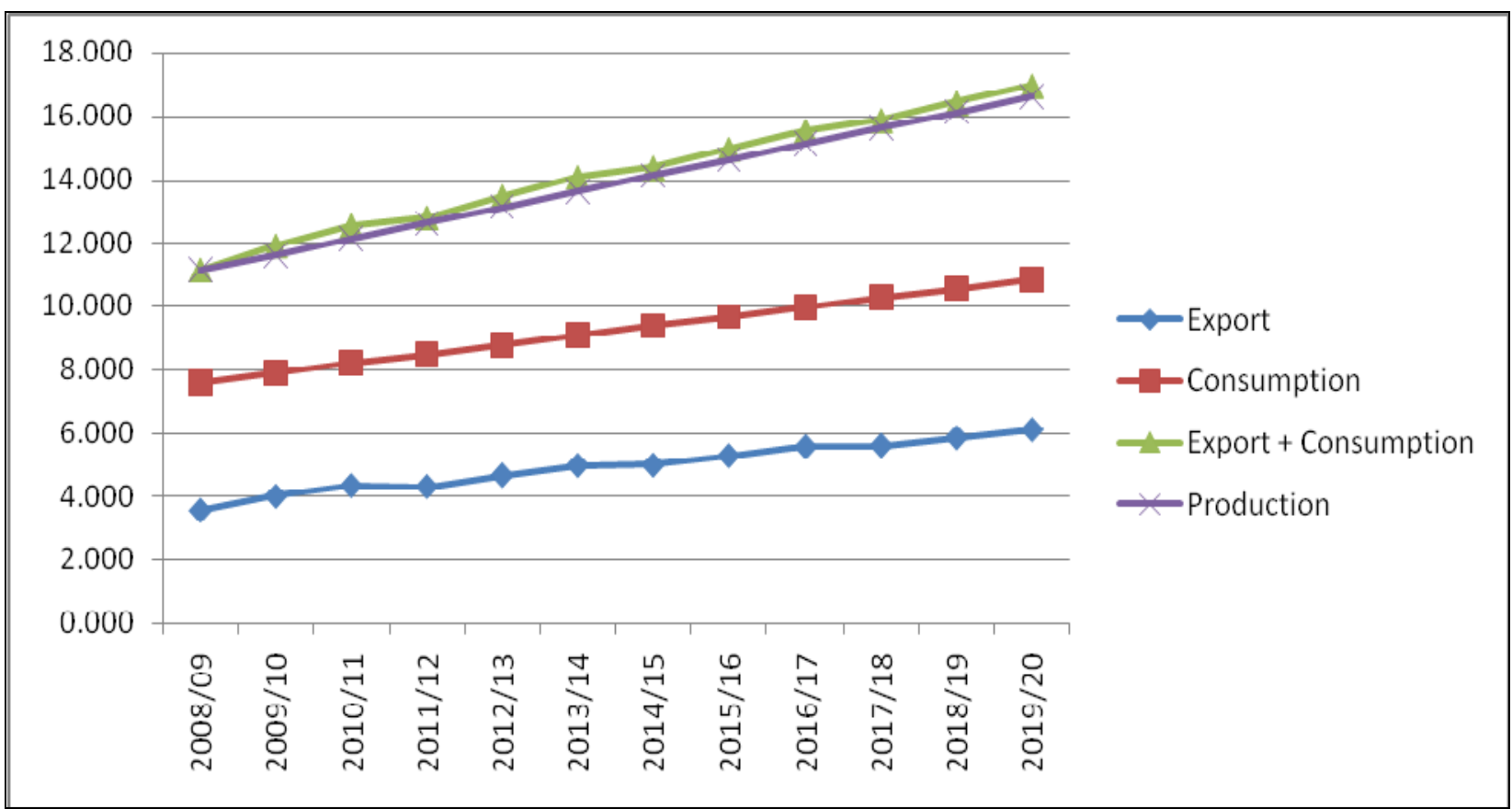

Fig. 5 Projection of the Brazilian poultry industry for the period 2010/2020 (million tonnes). Source: Ref. [6]. 
Considering the average rate of economic growth in past decade (9.6\%) and the growth projection for 2010 reaching 7\% [47], it is noticed that China is following, in general, the steps of the countries known as "Asian Tigers", which invested great part of available resources in technology, education and maintenance of the currency to balance the domestic economy.

\subsection{China-Brazil Market}

The consolidation of China as the main business partner for Brazil, ahead of the United States represents both a challenge and an opportunity. Nowadays being the second biggest economy in the world [47], the Asian country, even facing the economic crisis that toppled the North American and European economy, keeps a strong economic growth, considerable improvement in income and its distribution and an accelerated urbanization, factors which promote euphoria in exporting countries like Brazil.

The market between China and Brazil is growing fast. In the last ten years (1999-2008) the shipping of national products to China raised more than 18 times, jumping from US\$ 905 million to US\$ 16.4 billion. During the first semester of 2009 (height of the global crises), the sales to China grew $41 \%$ reaching practically US\$ 10.4 billion [3].

These Brazilian exports are essentially commodities, for example iron ore and soybeans. On the other hand the Chinese send us a diverse range of industrial products, such as electronics, shoes, toys and parts [7].

When analyzing the Brazilian productive potential and the need for products of agri-feeding source that China has, it is perceived that the Chinese market shows conditions to become the focus of several agro-industrial productive chains in Brazil, considering that the country becomes more industrial because of the agricultural production and the population continue to grow [7].

One of the agro industrial chains that best show conditions to profit from the closer commercial ties between Brazil and China is the poultry chain. Brazil is the third biggest producer of poultry (behind only of the U.S and China itself) and since 2005 Brazil is the biggest exporter, being that in the year 2009 the Brazilian exports represented $38.5 \%$ of the global exports of poultry meat [3].

The Brazilian exports of poultry to China is still small and incipient compared to China's import capacity but it increased $4.991 \%$ in the last three years, going from 980 tonnes in 2008 to 48.920 tonnes until June 2010 [6].

China has increased its poultry production but this bigger volume has not proportionally followed the growth in the annual consumption for their population [7], that went from $7.6 \mathrm{~kg} /$ year in 2004 to $9.1 \mathrm{~kg} /$ year in 2009 and with a forecast to reach $25.2 \mathrm{~kg} /$ year in 2022 [46]. Consequently, China has been having decreases in its poultry and derivatives exports (reduction of 23.5\%) and expanding the import of poultry meat getting to a total of 360 thousand tonnes in the year 2010, what represents an increase of $39.1 \%$ comparing to the year 2005 [46].

Even with the need to get the chicken meat through import, China imposes several requirements to its potential suppliers mainly related to sanitary issues [48] and trade barriers including import quotas [47]. One example of recent restrictions to the import of poultry products was the epidemic of bird flu (contagious disease that affects birds and possibly humans) that stroke Asia, Europe and Africa but did not cause problems in Brazil [6].

\section{Materials and Methods}

Considering the proposed objective, the chosen method was literature research (documentary and descriptive), done in international and national research bases, using original articles, review articles, books, websites and governmental and private reports, written in English and Portuguese.

Secondary quantitative and qualitative data were used to analyse the production and commercialization of global poultry industry associating them to the current and future Chinese demand for Brazilian 
poultry products, outlining possible production and commercial perspectives according to the model proposed by Grunert [8], which associates the Theory of Market Orientation with the Theory of Value Chain.

In this model (Fig. 6), the author lists the defining characteristics that allow to identify the market orientation of a value chain.

The defining characteristics proposed in the Model of Grunert [8] and used in the study present the following conceptual definitions:

Competitive pressure: the difference between the levels of market orientation of companies many times relate to the differences in competitive pressures experienced by them when they enter the market.

Heterogeneity and dynamism of the final consumer, the greater the ability to offer products across the value chain further expands the benefits for all links seen that the market becomes dynamic allowing news technologies to be developed, the expansion of production volume and the price to become competitive due to the competition.

Associations inter-firm market-oriented: the associations of inter-firms (commercial or not), may have an important role in the generation of market intelligence, also influencing the formation of mental models for an entire industry. As trade associations develop their activities in a market-oriented way which influences the market orientation degree of the whole value chain involved.

Regulation: regulation of markets facilitates the understanding of the rules for the supply and demand for products. Commercial Transactions in international chains are often regulated by quotas, minimum price agreements and contracts.

Mental models: the value chain participants negotiate and make decisions based on prior knowledge, trust in their commercial partner, performance and competitiveness, perception of product quality over the competition and the importance of the product for itself.

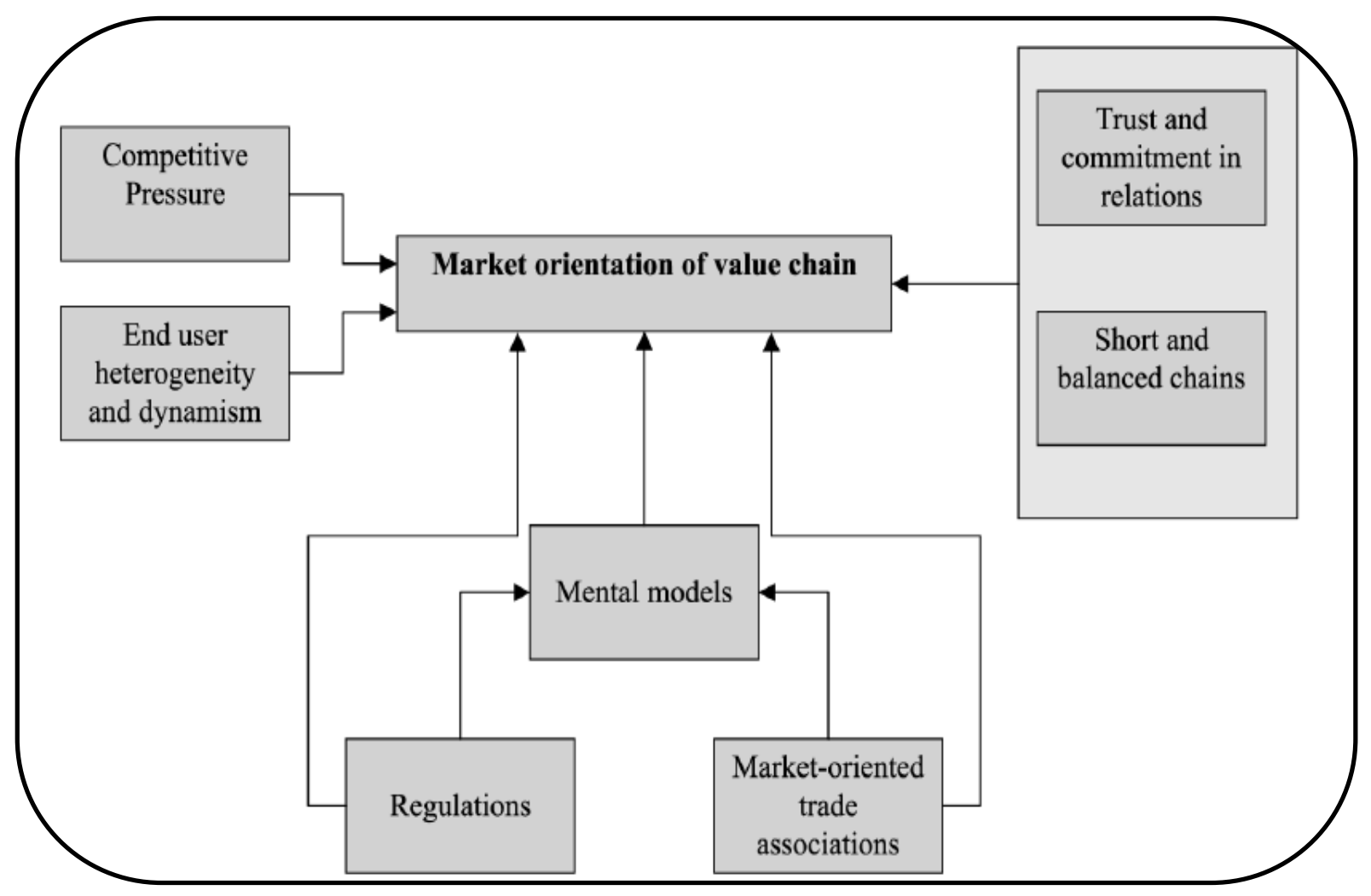

Fig. 6 Defining characteristics of the market orientation in a value chain.

Source: Grunert [8] adapted by author. 
Short and balanced chain: when the value chain is controlled by one of the sectors involved it allows a better development of the market orientation and the balance among participants facilitating the current and future negotiations.

Trust and commitment in relationships: when there are trust and commitment among the sector involved in the value chain, it increases significantly the exchange of information and to reduce possible problems that prevent participant members of the chain from developing activities to improve the processes upstream and downstream.

\section{Results and Discussion}

The supply chain associated with the value chain of the modern poultry industry allows an analysis of the international market for poultry meat, through specific characteristics of each country that supplies or demands this product considering the aspects of globalization [49], food safety [50] and competitive prices [16].

The market orientation becomes a key requirement to maintain and attract new customers [34]. In the poultry chain the volume of production, the quality of the product and the trust between the parties become a competitive advantage for the participants of the market [51], besides the use of trade agreements ensuring bilateral trade or even allowing the maintenance of prices and the guarantee of exchange between the countries.

China is a promising market because the poultry meat serves all social classes, including the less advantaged, corresponding to about one billion Chinese that have recently started to increase the consumption and seek in the chicken meat an alternative to fulfil their need of protein.

A considerable part of the volume of Brazilian poultry exports to China entering in the port of Hong Kong and then be distributed to Chinese provinces. In 2009, Hong Kong bought 428.3 thousand tonnes of poultry meat from Brazil [2] and these values end up not being considered as Chinese demand, which could mean an even greater consumption of chicken than the statistics indicate.

Basing the study in the literature review, in the theories used and the model proposed by Grunert [45], 10 characteristics and/or factors in the value chain of the national poultry industry that fit the demands of Chinese market were listed (Table 4), and enable competitive advantage of Brazilian poultry exporters before other exporting countries to meet the market guidelines that China signals in the present.

For a better comprehension of the characteristics found in the study, a brief description of each of them is presented below:

Integrated production chain: poultry production for export in Brazil is concentrated in large agro-industrial groups (ex.: Brazil Foods, Tyson Foods, Marfrig) that control great part of the links of the value chain in a direct (feed mill, hatchery, technical assistance, fridge) or indirect way (poultry production, logistics, distribution). The chain is classified as short and

Table 4 Comparison between the proposed characteristics in the model of Grunert [45] and the ones found in the study of the value chain of the Brazilian poultry oriented to the China exports.

\begin{tabular}{ll}
\hline Characteristics of the model of Grunert [45] & Caracteristics found in the study that fit the model of Grunert \\
\hline Competitive pressure & Exporter Know-how/Volume of production/Competitive price \\
Heterogeneity and dynamism of the final consumer & Technology domain/Production volume/Exporter Know-how \\
Mental models & Competitive price/ Brazil-China trade agreements \\
Oriented trade associations & Expanding Chinese demand/ Potential and productive expansion \\
Regulations & Brazil-China trade agreements/ Sanitary conditions \\
Short and balanced chains & Integrated production chain \\
Trust and commitment in relationships & $\begin{array}{l}\text { Potential for production expansion/ Exporter Know-how/ Brazil-China trade } \\
\text { agreements }\end{array}$ \\
\hline
\end{tabular}

Source: By author (2010). 
balanced and allows a vertical and horizontal integration, reducing costs and enhancing the quality control of products.

Potential for production expansion: the possibilities of production expansion are materialized by the large number of plants that spread all over the country, besides the production of grains evolving year after year. The internationalization of Brazilian industry of meat agribusiness increases the possibilities of expanding production for the whole chain, allowing the country to increase the international competitiveness.

Exporter Know-how: Brazil is currently the biggest poultry exporter (approximately $40 \%$ of global exports) reaching 154 countries (UBA, 2009) and with real perspective for expanding this share in the global market. The country has factories aimed to provide a wide variety of products directly to the foreign market, allowing the export of different cuts and derivatives of poultry. The production differential in Brazil is the ability to orient themselves to the market and suit the most diverse and demanding requests of buyers.

Brazil-China trade agreements: commercial relations between the two countries were recently extended with the signature of many uni and bi-lateral trade agreements and real perspectives of future agreements including the ones to export Brazilian meat to China and consequently opening opportunities for poultry and its derivatives (whole chicken, cuts, giblets, cooked and processed products). New trade agreements are needed to consolidate the market for Brazilian chicken for China.

Technological domain: Brazil is a world leader in technological development for the poultry production chain. EMBRAPA (Brazilian Agricultural Research Corporation) is a reference in international agricultural research, besides the fact that Brazil presents results of field production well above the world average (feed conversion, mortality, daily weight gain). Several national metallurgical companies export equipment for poultry farms and slaughterhouses, reaching practically every corner of the world with all kinds of products and technologies.

Competitive prices: the country has an expanding grain production (reduced feed costs), expanding farmland, cheap labour force when compared to the main exporting competitor countries, control of infectious diseases (Marek's disease, influenza, Gumboro) that compromise the production and increase its costs, industrial park installed and expanding. All this makes the Brazilian chicken cheap when comparing sales prices in foreign markets.

Expanding Chinese demand: with a population of 1.3 billion people, population growth of $0.6 \%$ per year concentrated in large urban centres and with dizzying decline of the rural population China currently needs to import food and the natural tendency is to increase the imports year after year.

Production volume: Brazil is the third biggest producer of poultry in the world and is expanding its productions, thus ensuring it meets the demands of importing countries.

Sanitary conditions: Brazil fulfils the sanitary and hygienic terms to export the meat to China. Besides that, there are no records of outbreaks of avian influenza (influenza) that hit the world production recently (2008) and also no record of outbreaks of Marek's disease. The Brazilian system for animal health protection is recognized worldwide for its ability to control and prevent infectious diseases. China still imposes contractual restraints on poultry produced in Brazil but there are already 24 slaughterhouses enabled and habilitated by the Chinese government to export directly to the country and the other national slaughterhouses are adapting to the Chinese terms.

Besides these characteristics of the value chain of Brazilian poultry farming, another aspect that should be taken into account for the final opening of trade with China is the solid marketing relationship existent between the Chinese and the North Americans including in the trade of poultry meat and derivatives but that has been facing trading impasses.

The reduction in the offer of poultry from the U.S. to 
China is actually becoming a reality since 2009, but the Chinese government has signalled that will restrain even more the imports of American meat due to, macroeconomic factors (especially with applying anti-subsidy rates and anti-dumping) and the balance in the trade balance [47]. Nowadays, there is no other country to substitute the USA in offer and sanitary conditions requested by China than Brazil.

To understand the market for poultry between Brazil and China, a framework (Fig. 7) was built, which demonstrates the characteristics and factors found and that influence the negotiations considering the current reality and future perspectives.

The characteristics found in the value chain of Brazilian poultry meet the demands of the Chinese market orientation, and need to be kept by the country to consolidate the current and future negotiations. The market factors in the chain that need to be negotiated between the two countries are in the Chinese current needs, but must be regulated and signed in contracts and agreements.

The market factors that need to be considered in negotiations Brazil/China involve issues outside the chain of Brazilian poultry, because they depend on the demand from China and international trade agreements of the Chinese. Considering the current situation of the poultry industry, Brazil has great conditions to consolidate itself as an exporter of poultry meat and derivatives to China.

\section{Conclusion}

Brazil has real conditions to continue increasing its annual poultry and derivatives production, consolidating its position as the leading country in exporting poultry. In contrast, China presents a growing demand for poultry but requires from their suppliers high technological standards and production volume, guarantee of sanitary quality and hygiene and competitive prices.

The national poultry chain has real conditions to attend the Chinese demands, but it is necessary to regulate the export rules and settle import contracts.

The aspects which limit the relation Brazil-China for the trade of poultry are unilateral or bilateral trade agreements which are still incipient, and the strong commercial connection between China and the United

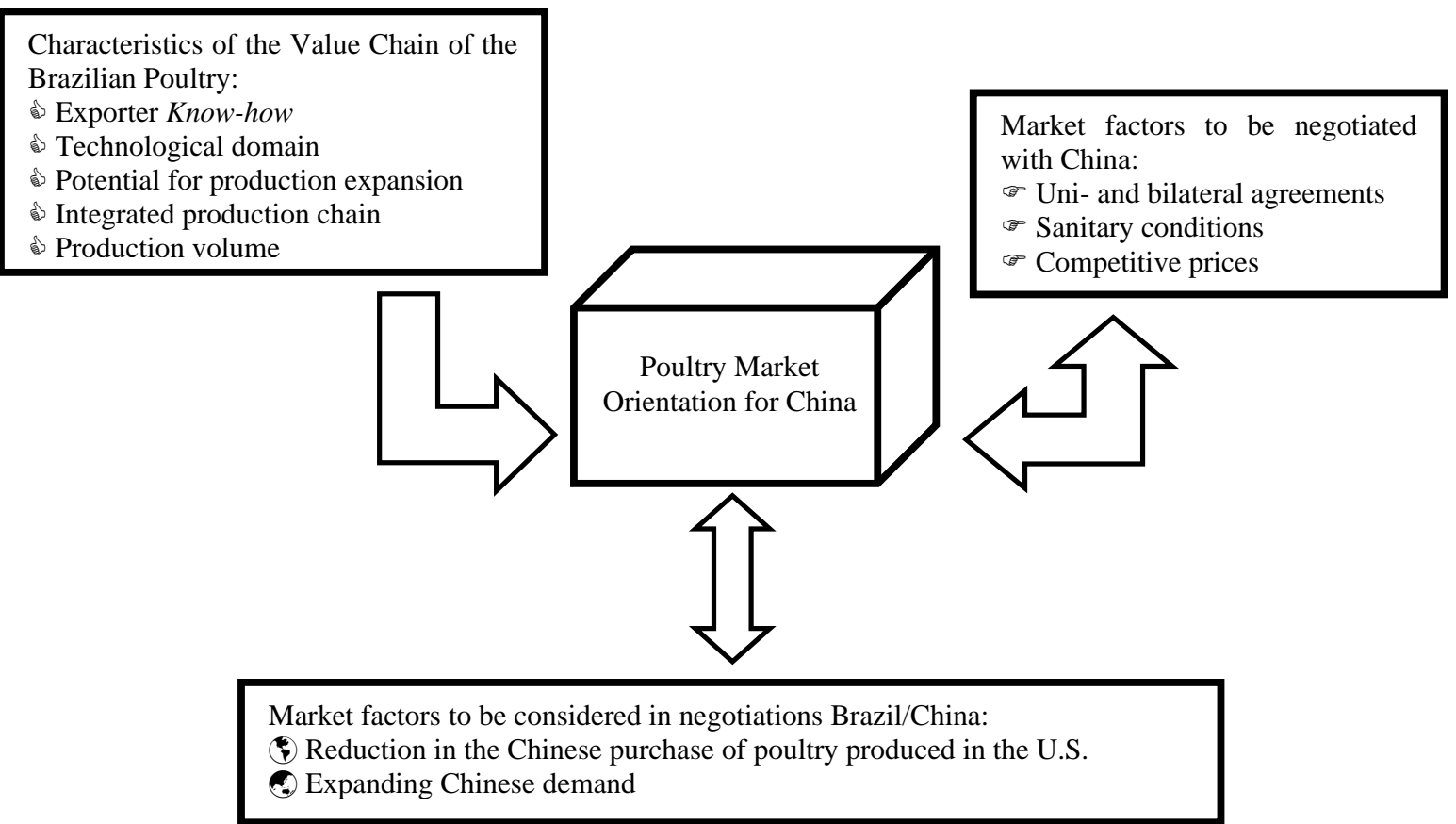

Fig. 7 Framework of the determining characteristics and the marketing factors found in the study about market orientation of the chain value of the Brazilian poultry for China.

Source: By author (2010). 
States for this product, although China has been restricting the American poultry imports.

Considering the Theory of Market Orientation, it is concluded that Brazil has effective conditions to consolidate itself as a major supplier of chicken meat and derivatives to China, because it shows determinant characteristics and market factors that allows the association of the national poultry value chain to the demands of the Chinese consumers, but some adjustments are needed in the sphere of international politics.

\section{References}

[1] USDA, United States Department of Agriculture, Livestock and Poultry: World Markets and Trade, Trade Forecast Revision: Pork Higher, Beef and Broiler Meat Stable, 2010, http://www.fas.usda.gov/psdonline/circulars/livestock_po ultry.pdf.

[2] UBA, União Brasileira de Avicultura, Annual Report-2009 [online], 2009, available online at: http://www.abef.com.br/uba/uba_relatorios_anuais.php. (in Portuguese)

[3] MAPA, Ministério da Agricultura, Pecuária e Abastecimento-Brazil, Agribusiness trade: Main destination markets, MAPA/ACS, Brasília, 2009. (in Portuguese)

[4] EMBRAPA, Technical Report of Activities 2009 Embrapa Pig and Poultry, CNPSA/EMBRAPA, Concórdia, 2010. (in Portuguese)

[5] E. Deliberali, G. Viana, J.R. Staduto, R. Rinaldi, Exports and qualifications of chicken meat to the international market: A study of middle region west of the state of Parana, Informações Econômicas 40 (2010) 18-30. (in Portuguese)

[6] MAPA, Ministério da Agricultura, Pecuária e Abastecimento-Brasil, Projections of agribusiness: Brazil 2009/2010 a 2019/2020, MAPA/ACS, Brasília, 2010. (in Portuguese)

[7] National Bureau of Statistics of China, The Central People's Government of the Peoples Republic of China, 2010, http://www.stats.gov.cn/english/index.htm.

[8] K.G. Grunert, L.F. Jeppesen, K.R. Jesppesen, et al., Market orientation of value chains: A conceptual framework based on four cases studies from the food industry, European Journal of Marketing 39 (2005) 428-455.

[9] S.F. Slater, J.C. Narver, Does competitive environment moderate the market orientation-performance, Journal of
Marketing 58 (1) (1994) 46-55.

[10] B.J. Jaworski, A.K. Kohli, Marketing orientation: Antecedents and consequences, Journal of Marketing 57 (1993) 53-70.

[11] J.A. Siguaw, G. Brown, R. E. Widing II, The influence of the marketing orientation of the firm on sales force behavior and attitudes, Journal of Marketing Research 31 (1994) 106-116.

[12] S.D. Hunt, R.M. Morgan, The comparative advantage theory of competition, Journal of Marketing 59 (1995) 1-15.

[13] R.A. Morgan, S.D. Hunt, The commitmenttrust theory of relationship marketing, Journal of Marketing 58 (1994) 20-38.

[14] S.D. Hunt, C.J. Lambe, Marketing's contribuition to business strategy: Marketing orientation, relationship marketing and resource-advantage theory, International Journal of Management Reviews 2 (2000) 17- 43.

[15] S.F. Slater, J.C. Narver, Market orientation, customer value, and superior performance, Business Horizons 37 (1994) 22-28.

[16] B.A. Wagner, J.A. Young, Seabass and seabream farmed in the Mediterranean: Swimming against the tide of market orientation, Supply Chain Management 14 (6) (2009) 435-446.

[17] J. Narver, S.F. Slater, The effect of a marketing orientation on business profitability, Journal of Marketing 54 (1990) 20-35.

[18] A. Pelham, Market orientation and other influences on performance in small and medium-sized manufacturing firms, Journal of Small Business Management 38 (2000) 48-67.

[19] F. Webster, Executing the new marketing concept, Marketing Management 3 (1) (1994) 8-20.

[20] B. Jaworski, A.K. Kohli, A. Sahay, Market-driven versus driving markets, Journal of Academy of Marketing Science 28 (1) (2000) 45-54.

[21] B. Shapiro, What the hell is marketing oriented, Haward Business Review 66 (1988) 119-125.

[22] A.K. Kohli, B.J. Jaworski, Market orientation: The construct, research propositions, and managerial implications, Journal of Marketing 54 (1990) 1-18.

[23] B.J. Jaworski, A.K. Kohli, Market orientation: Review, refinement, and roadmap, Journal of Market-Focused Management 1 (1996) 119-136.

[24] G. Day, The capacities of market-driven organizations, Journal of Marketing 58 (1994) 37-52.

[25] R. Deshpandé, J.U. Farley, Measuring marketing orientation: Generalization and synthesis, Journal of Marketing Focused Management 2 (1998) 213-232.

[26] A. Foley, J. Fahy, Incongruity between expression and 
experience, Journal of Brand Management 11 (2004) 258-271.

[27] W. Baker, J.M. Sinkula, Market orientation and the new product paradox, Journal of Product Innovation Management 22 (2005) 483-502.

[28] G.F. Gebhardt, G.S. Carpenter, J.F. Sherry, Creating a market orientation: A longitudinal, multi-firm, grounded analysis of cultural transformation, Journal of Marketing, 70 (2006) 37-55.

[29] M.A. Farrell, Developing a market-oriented learning organisation, Australian Journal of Management 25 (2) (2000) 201-222.

[30] V. Vieira, Antecedents and consequences of market orientation: A Brazilian meta-analysis and an international mega-analysis, Brazilian Administration Review 7 (1) (2010) 40-58.

[31] E. Kuazaqui, International marketing, M. Books, São Paulo, 2006. (in Portuguese)

[32] G.E. Osland, C.R.E. Taylor, S. Zou, Selecting international modes of entry and expansion, Marketing Intelligence e Planning 19 (3) (2001) 153-161.

[33] A.P. Macera, A.T. Urdan, Guidance for the foreign market: Testing a model in Brazil and its application to a sample of Brazilian exporters, Revista de Administração Contemporânea 8 (2) (2004) 95-115. (in Portuguese)

[34] M.E. Porter, Competitive advantage: Creating and sustaining superior performance, Rio de Janeiro: Campus, 1989. (in Portuguese)

[35] J.D.S. Diniz, N. Fabbe-Costes, Supply chain management and supply chain orientation: Key factors for sustainable development projects in developing countries?, International Journal of Logistics: Research and Applications 10 (2007) 235-250.

[36] J.W. Cadogan, A. Diamantopoulos, Narver and Slater, Kohli and Jaworski and the market orientation construct: Integration and internalization, Journal of Strategic Marketing 3 (1995) 41-60.

[37] S. Zou, C.R. Taylor, G.E. Osland, The experf scale: A cross-national generalized export performance measure, Journal of International Marketing 6 (3) (1998) 10-15.

[38] J.W. Cadogan, A. Diamantopoulos, C.P. De Mortanges, A measure of export marketing orientation: Scale development and cross cultural validation, Journal of International Business Studies 30 (4) (1999) 689-707.

[39] K. Matsuno, J.T. Mentzer, The effects of strategy type on the market orientation performance relationship, Journal of Marketing 64 (2000) 1-16.

[40] I.L. Garrido, Guidance for the foreign market: The refinement of a measurement scale, Revista de Administração de Empresas 47 (4) (2007) 116-130. (in Portuguese)

[41] M. Dalmoro, Factors related to the internationalization process of influencing the external marketorientation and export performance, Sinergia 11 (2) (2007) 41-52. (in Portuguese)

[42] D. Kupfer, L. Hasenclever, Industrial Economics, Campus, Rio de Janeiro, 2002. (in Portuguese)

[43] M.J. Baker, Editorial, Journal of Marketing Management 15 (1999) 211-214.

[44] K.G. Grunert, L.F. Jeppesen, K. Risom, et al., Market orientation at industry and value chain levels: Concepts, determinants and consequences, Journal of Customer Behaviour 1 (2) (2002) 167-194.

[45] K.G. Grunert, T. Trondsen, E.G. Campos, Market orientation in the mental models of decision makers: Two cross-border value chains, International Marketing Review 27 (1) (2010) 7-27.

[46] USDA, United States Department of Agriculture, Export Requirements for People's Republic of China 2010, 2009, http://www.fsis.usda.gov/psdonline/psdHome.aspx, (accessed 2010). (in Portuguese)

[47] World Bank, China, 2010, http://www.worldbank.org/cn.

[48] L.L. Xu, L.H. Wu, Food safety and consumer willingness to pay for certified traceable food in China, Journal of the Science of Food and Agriculture 90 (8) (2010) 1368-1373.

[49] L. Manning, R.N. Baines, Globalisation: A study of the poultry meat supply chain, British Food Journal 106 (2004) 819-36.

[50] L. Manning, R.N. Baines, Effective management of food safety and quality, British Food Journal 106 (8) (2004) 598-606.

[51] L. Manning, R.N. Baines, S.A. Chadd, Benchmarking the poultry meat supply chain, Benchmarking-An International Journal 15 (2008) 1463-1471. 